\title{
Adaline and FIS Techniques for Fault Identification in HV Transmission Line
}

\author{
K. Elango' ${ }^{1}$, G. Geetha ${ }^{2}$ \\ ${ }^{1}$ Department of EEE, Valliammai Engineering College, Chennai, India \\ ${ }^{2}$ Department of EEE, Annai Mira College of Engineering, Chennai, India \\ Email: drkelango@yahoo.com, geethaganesan27@gmail.com
}

Received 12 May 2016; accepted 20 May 2016; published 23 August 2016

Copyright (C) 2016 by authors and Scientific Research Publishing Inc.

This work is licensed under the Creative Commons Attribution International License (CC BY).

http://creativecommons.org/licenses/by/4.0/

c) (i) Open Access

\begin{abstract}
This paper is to identify and classify the various types of shunt and line faults in transmission line. The faults may be an insulation failure, lightning or accidental faulty operation. In a transmission line protection important factor is identifying a fault because if any error occurs in finding fault may leads to abnormal operation of the protection system. So either a disturbance or steady state variation is called power quality variation. The proposed test system is modeled based on the neural network and fuzzy algorithm. The online symmetrical components are extracted by this above algorithm. The fuzzy is used to separate the oscillating components and average components. Here input for the fuzzy is trained by using neural network. It is based on current samples and very effective in fault classifier using rule base. This method is very much suitable for online implementation.
\end{abstract}

\section{Keywords}

Symmetrical Components, Fuzzy, Fuzzy Interference System, Transmission-Line Protection

\section{Introduction}

In power systems, electrical transmission line has an important role which may be subjected to various disturbances like short circuit by any phase damage or lightning. The protective relays are based on three principle modules as fault detection, fault classification and fault location [1]. In fault classification, it determines the exact type of fault [2]. The fault detection and fault classification are important devices if error in fault detection leads to failure of the protection systems. So, this accidents occur in high voltage transmission line is protected by protective relay.

In this, there may be transient in measured signal which always results in symmetrical components with error 
is seen [3] [4]. Linear methods are used for Fault protection, which is based on symmetrical components and unbalanced current. To improve the performance we are going for adaptive protection concept is used [5].

Generally the main objective of the protective relay is to protect the equipment by making it out of service during phase and ground fault [6]. If it fails to work, it means that the transmission system components get unproductive. The adaptive protection techniques are developed with wavelet transformation artificial, neural network and fuzzy logic [7] [8]. Here fuzzy logic controllers are used. This is based on current samples. In a power system the protective relaying is one of the basic components.

Sometimes it causes hazards to the human being and also to the equipment during the fault MVA is high, thus it should be cleared as soon as possible. Therefore there should be a better fault identification is needed, thus this proposed system is carried out. The followings are various demerits of the conventional system.

In conventional algorithm, using discrete Fourier analysis may leads to have transients in measured signal. In wavelet transform it have complex in symmetrical components computation. Similarly, in ANN-artificial neural network needs more training data for real time application [9] [10]. In Adaline based neural network needs the large number of phasor input for training such that it results in inaccuracies during the various phase faults [11] [12].

\section{Fault Identification in High Voltage Transmission Line}

The Adaline is the one of the adaptive technique in the neural network which has used for many applications especially for fault identification in high voltage transmission line [1]. It is used for permanent and transient faults. The Adaline method uses a single neuron with multiple inputs and with one output or has a linear activation function [12]. Four number fuzzy inference system and Adaline are used for fault identification. So if the combination of both neural network and fuzzy results in the both low and high impedance faults are identified with in the half cycle of period. The output of this Adaline is compared to the desired values. The fuzzy rules are formed based on instantaneous p-q theory. As in Adaline, here four fuzzy blocks are used for the direct current computation as well as inverse current computation. For direct and inverse current computation, angle is taken from phase locked loop [13].

\subsection{Fuzzy in Transmission Line Protection}

The Fuzzy Logic allows doing several things, but the most important thing it lets creates and edits fuzzy inference systems. In the matlabsimulink this simulation block diagram can be easily test the fuzzy logic controller. This given system can be done by MATLAB Simulink or by using neuro fuzzy techniques [14].

In this paper, all the fuzzy set is defined by extending the classical set [15]. If $\mathrm{X}$ is the universe of discourse and its elements are denoted by $\mathrm{x}$, then aA be the fuzzy set in the given universe of discourse.Let membership function is given by MF or $\mathrm{x}$ in A. The membership value always lies between 0 and 1 . Generally in fuzzy interference system there are two types of expert system namely Sugeno type and Mamdani type both are varied by its outputs. The process of mapping all the input to an output is carried out by fuzzy logic controller. Hence based on the mapping all the decision is done as classifying the various line and shunt faults.

The first step in classifying fault is to take the input transmission line currents, and also it finds the angle. Here trapezoidal membership functions used. This model is developed in MATLAB software using fuzzy logic tool box [16]. From the input real and reactive power is calculated by using current and voltage from phase locked loop. The fuzzy rule is formed by applying fuzzy operator. The output of the membership function is shaped on the basis of firing strength of the rules. The product and minimum are most commonly used implication method. Raw data is extracted using Takagi-Sugeno system. It is developed by human expert systems that are purely linguistic rather than numerical data this steps are carried out as shown in Figure 1.

Each rule of the output is added together by the process of aggregation. Implication process is performed by aggregation of truncated output. Defuzzifier is defined as the aggregated output of fuzzy set. In defuzzification

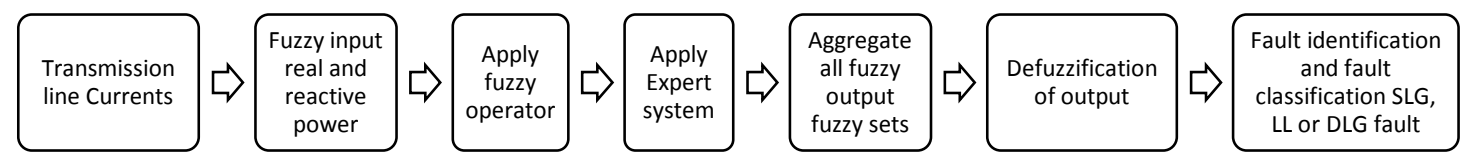

Figure 1. Flowchart for fault identification. 
process is the simplest and commonly used is gravity method. The information of all the inputs are combined to a single non fuzzy output which finds the type of fault occurred in transmission line. In this paper the membership functions are taken as a high, normal and low as fault range. It is denoted as follows: $\mu 1, \mu 2$, and $\mu 3$.

\subsection{Symmetrical Components Computation}

Positive, negative and zero sequence terminology is used as "Direct, inverse and zero" terminology. The complexity of the differential equations can be reduced by changing variables. Clarke transformation is used for the stationary circuits to the stationary reference frame.

Here $\alpha$ and $\beta$ are represented as a two phase stationary variables in Clarke's transformation, $\beta$-axis and $\alpha$-axis are orthogonal. For easy analysis transformation is carried out and by using following equation three phase current value is transformed to two phase. This helps to classify the different line and shunt faults occurred in line. The resulting transformation is:

$$
\begin{gathered}
{\left[f_{\alpha \beta 0}\right]=T_{\alpha \beta 0}\left[f_{a b c}\right]} \\
T_{\alpha \beta 0}=\frac{2}{3}\left(\begin{array}{ccc}
1 & -\frac{1}{2} & -\frac{1}{2} \\
0 & \frac{\sqrt{3}}{2} & -\frac{\sqrt{3}}{2} \\
\frac{1}{2} & \frac{1}{2} & \frac{1}{2}
\end{array}\right)
\end{gathered}
$$

Here we consider positive sequence current as a direct current, negative sequence current as an inverse current in Figure 2. This current is calculated based on following equation:

$$
\left(\frac{i_{\alpha}}{i_{\beta}}\right)=\sqrt{\frac{2}{3}} C_{32}^{T} I_{a b c}
$$

Then the real and reactive power is computed separately for direct and inverse components by following equations:

$$
\begin{aligned}
\left(\begin{array}{c}
p_{d} \\
q_{d}
\end{array}\right) & =\left(\begin{array}{cc}
V_{\alpha d} & V_{\beta d} \\
V_{\beta d} & -V_{\alpha d}
\end{array}\right)\left(\begin{array}{l}
i_{\alpha d} \\
i_{\beta d}
\end{array}\right) \\
\left(\begin{array}{c}
p_{i} \\
q_{i}
\end{array}\right) & =\left(\begin{array}{cc}
V_{\alpha i} & V_{\beta i} \\
V_{\beta i} & -V_{\alpha i}
\end{array}\right)\left(\begin{array}{l}
i_{\alpha i} \\
i_{\beta i}
\end{array}\right) \\
P_{d} & =V_{\alpha d} i_{\beta d}+V_{\beta d} i_{\beta d} \\
P_{i} & =V_{\alpha i} i_{\beta i}+V_{\beta i} i_{\beta i}
\end{aligned}
$$

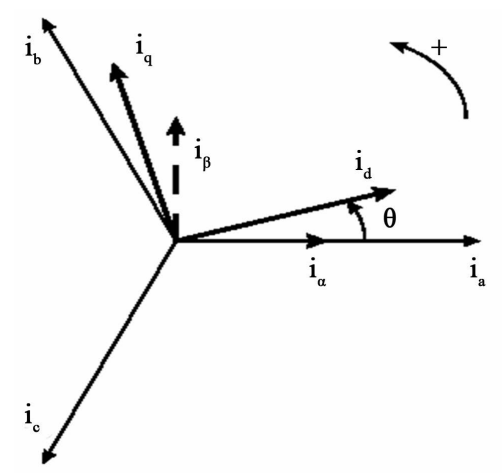


where power is taken as $p=3 I \cos \Phi$ and reactive power is $q=3 I \sin \Phi$. The overall block diagram is given below; it uses instantaneous power theory for computing active and oscillating power after fault. The source voltage is taken as $200 \mathrm{kV}$ at frequency of $50 \mathrm{~Hz}$. Let the transmission line length is consider as either $50 \mathrm{~km}$ or $100 \mathrm{~km}$. Here $386.4+\mathrm{j} 293 \mathrm{~m} \Omega / \mathrm{km}$ is taken as homopolar sequence impedance $\left(Z_{0}\right), 12.73+\mathrm{j} 293 \mathrm{~m} \Omega / \mathrm{km}$ is taken as direct sequence impedance $\left(Z_{d}\right)$. The simpower system toolbox is used to analysis test system for different cases.

The Phase locked loop estimate voltage and phase angle by feedback loop. The reactive and real power is determined by using instantaneous power theory. Here fuzzy block is used separately for direct current computation and inverse current. The above functional block diagram Figure 3. As two sources connected through a transmission lines .Instantaneous current values is taken from three phase transmission line, then current is measured by using current transformer. Three phase current values are converted to two phase reference frame as $\alpha$ and $\beta$ by Clarke transformation.

In this test system Inverse Clarke transformation is used to get the three phase stationary reference frame from the two axis orthogonal stationary reference frame. Thus PLL is an electronic module which locks the output to the input. Here voltage is taken as input for the P-Q computation after clarke's transformation and phase angle is used by fuzzy logic controller for power calculations and to separate average and oscillating components. To get three phase current value following formula is used as shown below:

$$
\left(f_{0}\right)=T_{0}^{-1}\left(f_{a b c}\right)^{1}
$$

where,

$V_{a}, V_{b}, V_{c}$ are three-phase quantities.

$V_{\alpha}, V_{\beta}$ are stationary orthogonal reference frame quantities.

In this paper, frequency synthesis is done by using phase locked loop. This PLL is mostly used in communication applications. Generally we call phase locked loop as a feedback system its helps to detect the phase error and also it adjust the output phase. It consists of voltage control oscillator which adjusts the phase difference between two phases. Another important component is phase detector, which detects between the input and the output by using this PLL. Akagi [17] proposed a theory with or without neutral wire based on instantaneous values in a power system.

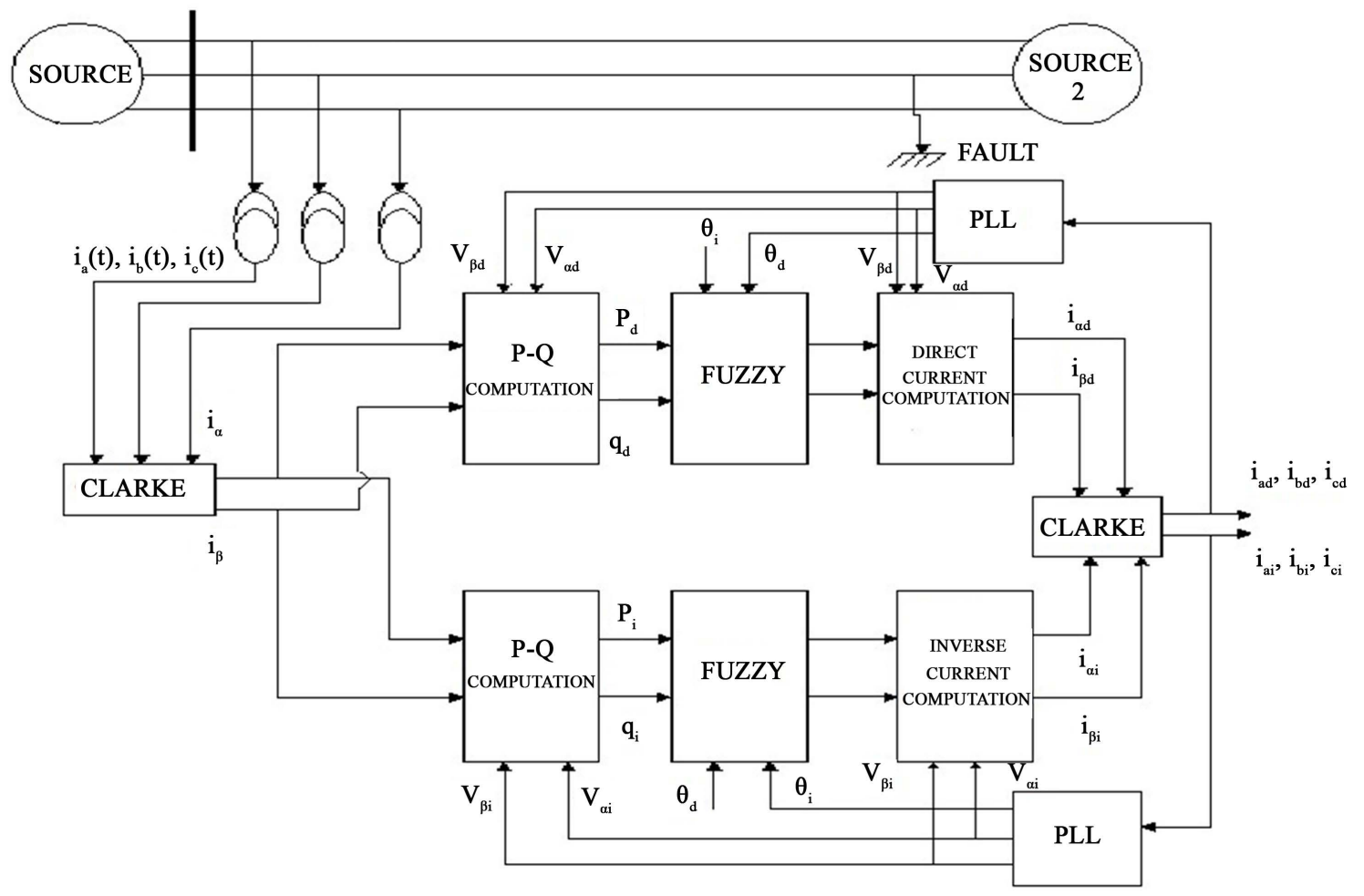

Figure 3. System under study for fault identification in transmission system. 
This theory is applicable only for the transient and also for steady state operations this generic current and voltage waveforms is called as Active-Reactive ( $p-q)$ theory or Instantaneous Power Theory (IPT). The power calculation of the $\mathrm{p}-\mathrm{q}$ theory power components that is three phase voltages in the a-b-c coordinates are converted to the $\alpha-\beta-0$ coordinates by using Clarke transformation or it is also called as an algebraic transformation in Figure 4. We consider fault transition time is taken from $0.3 \mathrm{sec}$ to $0.35 \mathrm{sec}$. Similarly for Adaline fault transition time is $0.04 \mathrm{sec}$ to $0.24 \mathrm{sec}$.

Where $V_{1} V_{2} V_{3}$ and $i_{1} i_{2} i_{3}$ are phase voltage and currents.

$$
\begin{gathered}
i_{p}=i_{1}+i_{2}+i_{3}=i_{0}(\sqrt{3}) \\
\left(\begin{array}{l}
i_{0} \\
i_{\alpha} \\
i_{\beta}
\end{array}\right)=\frac{\sqrt{2}}{\sqrt{3}}\left(\begin{array}{ccc}
\frac{1}{\sqrt{2}} & \frac{1}{\sqrt{2}} & \frac{1}{\sqrt{2}} \\
1 & -\frac{1}{2} & \frac{1}{2} \\
0 & \frac{\sqrt{3}}{2} & -\frac{\sqrt{3}}{2}
\end{array}\right)\left(\begin{array}{l}
i_{1} \\
i_{2} \\
i_{3}
\end{array}\right) \\
\left(\begin{array}{l}
i_{1} \\
i_{2} \\
i_{3}
\end{array}\right)=\frac{\sqrt{2}}{\sqrt{3}}\left(\begin{array}{ccc}
\frac{1}{\sqrt{2}} & 1 & 0 \\
\frac{1}{\sqrt{2}} & -\frac{1}{2} & \frac{\sqrt{3}}{2} \\
\frac{1}{\sqrt{2}} & -\frac{1}{2} & -\frac{\sqrt{3}}{2}
\end{array}\right)\left(\begin{array}{l}
i_{0} \\
i_{\alpha} \\
i_{\beta}
\end{array}\right)
\end{gathered}
$$

Where,

$p_{o}$ is the zero sequence real instantaneous power.

$p_{\alpha \beta}$ is the instantaneous value of real power.

$q_{\alpha \beta}$ is the instantaneous value of imaginary power.

This all are the above important concepts used in this paper for easy analysis of real and reactive power computation and also by considering harmonics from 1 to 60, which includes both odd and even harmonics has been proposed in this paper.

\subsection{Power Calculation by IPT}

The different power terms are defined as follows:

$$
\left(\begin{array}{c}
p_{0} \\
p_{\alpha \beta} \\
q_{\alpha \beta}
\end{array}\right)=\left(\begin{array}{ccc}
V_{0} & 0 & 0 \\
0 & V_{\alpha} & V_{\beta} \\
0 & -V_{\beta} & V_{\alpha}
\end{array}\right)\left(\begin{array}{c}
i_{0} \\
i_{\alpha} \\
i_{\beta}
\end{array}\right)
$$

Power components of the p-q theory in a-b-c coordinate the currents are obtained. By using instantaneous power theory in a stationary reference frame, the non-linear load currents and also main voltages are determined which is represented in a $\alpha-\beta$ component. In zero component current is assumed to be null value.

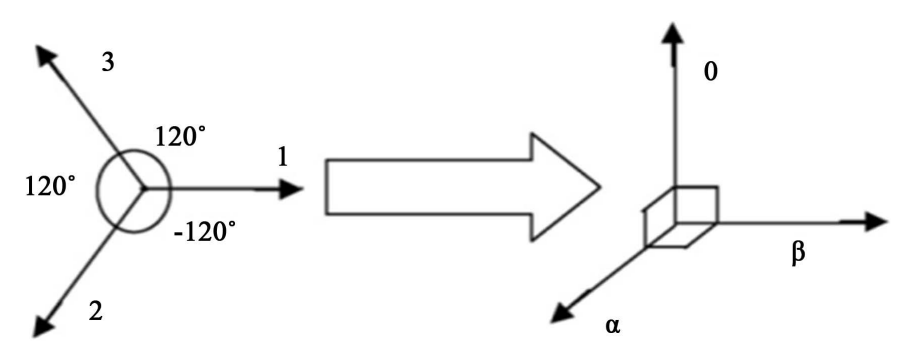

Figure 4. $0 \alpha \beta$ reference system. 


$$
\begin{aligned}
& \left(\begin{array}{l}
V_{\alpha} \\
V_{\beta}
\end{array}\right)=\frac{\sqrt{2}}{\sqrt{3}}\left(\begin{array}{ccc}
1 & -\frac{1}{2} & -\frac{1}{2} \\
0 & \frac{\sqrt{3}}{2} & -\frac{\sqrt{3}}{2}
\end{array}\right)\left(\begin{array}{l}
V_{1} \\
V_{2} \\
V_{3}
\end{array}\right) \\
& \left(\begin{array}{l}
i_{l \alpha} \\
i_{l \beta}
\end{array}\right)=\frac{\sqrt{2}}{\sqrt{3}}\left(\begin{array}{ccc}
1 & -\frac{1}{2} & -\frac{1}{2} \\
0 & \frac{\sqrt{3}}{2} & -\frac{\sqrt{3}}{2}
\end{array}\right)\left(\begin{array}{l}
i_{l 1} \\
i_{l 2} \\
i_{l 3}
\end{array}\right)
\end{aligned}
$$

The reactive and real load powers $p_{l}$ and $q_{l}$ are given:

$$
\left(\begin{array}{l}
p_{l} \\
q_{l}
\end{array}\right)=\left(\begin{array}{cc}
V_{\alpha} & V_{\beta} \\
V_{\beta} & -V_{\alpha}
\end{array}\right)\left(\begin{array}{l}
i_{l \alpha} \\
i_{l \beta}
\end{array}\right)
$$

\subsection{Fault Current Magnitude Calculation}

During single line to ground fault following equation is obtained. To check the test system efficiency and also the robustness by varying the length of the transmission line as $50 \mathrm{~km}, 100 \mathrm{~km}$ and $200 \mathrm{~km}$, and also by changing the load angle. If any line to line fault occurs in the power system then the time taken fault occurring is more due to the presence harmonics components. This is because of mutual impedance between the phases. Hence the derived equations under the line to line fault condition:

Similarly for line to line ground fault occurs at any point in a test system. Let we consider fault occur between the two phases as b and c, then the following are the equations derived during fault in a transmission line as given. The analysis of this different type of symmetrical components is used for the identification of nature of fault. During normal condition or any symmetrical fault conditions the zero sequence components and negative sequence currents are nearly equal to zero. The above procedure is used to classify the faults, in the three phase to ground fault in the beginning of the fault there will be presence of inverse and homopolar component current and it disappears at the end of the fault. The presence of only negative or inverse components represents the line to line fault has occurred in transmission line has been proposed in [12]. Similarly if negative or inverse component and zero or homopolar components presents in a transmission line be a double line to ground fault.

\subsection{Basic Consideration of Fault Identification}

Table 1 shows the different types of unsymmetrical faults which occurs in the transmission line. Whereas phase fault as the more fault current flow into the system rather than the ground fault. The symbol g represents the ground.

Table 1 shows the fault current magnitude estimated by the fuzzy interference system in an unloaded system. Fault occurs at $t=0.04 \mathrm{~s}$ to $\mathrm{t}=0.24 \mathrm{~s}$ and at the middle of the transmission line length $(\mathrm{L}=100 \mathrm{~km})$ with fault resistance of $R_{f}=20 \Omega$, the fault magnitude estimated from transmission system is less accurate which is very far away from the source. Thus, a complete fault identification and classification module is done using the fuzzy logic controller [18]. The Adaline is trained separately for the different single line to ground fault, line to line fault and double line to ground fault in Figure 5.

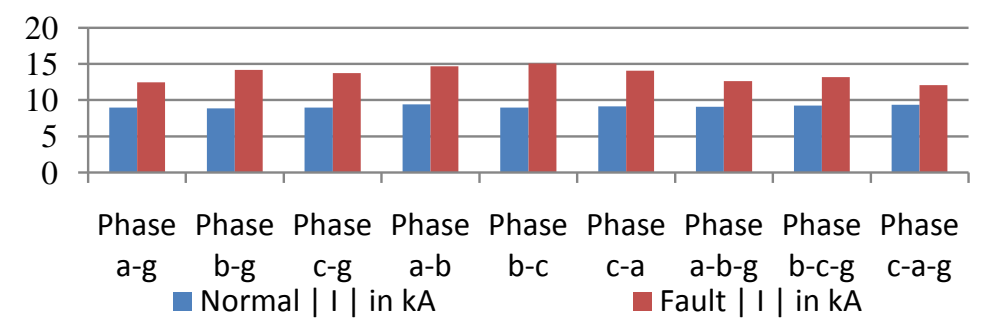

Figure 5. Various shunt fault identification. 
Table 1. Fault Identification by fuzzy in $100 \mathrm{~km}$ line.

\begin{tabular}{rcc}
\hline Type of fault & Normal |I| in kA & Fault|I| in kA \\
\hline Phase a-g & 8.958 & 12.473 \\
Phase b-g & 8.8887 & 14.207 \\
Phase c-g & 8.9533 & 13.74 \\
Phase a-b & 9.4061 & 14.654 \\
Phase b-c & 8.956 & 15.063 \\
Phase c-a & 9.1357 & 14.087 \\
Phase a-b-g & 9.083 & 12.615 \\
Phase b-c-g & 9.2432 & 13.17 \\
Phase c-a-g & 9.369 & 12.093 \\
\hline
\end{tabular}

\section{Results and Discussion}

\subsection{Performance of the FIS}

In this paper to identify the faults in transmission line is based on direct, inverse and homopolar currents. Here from 1 to 60 harmonics range is considered. It consists for both odd and even harmonic ranges, the following are the various results obtained during line and shunt faults as shown. In Figure 6 is the phase a to ground faults which shows the presence of both direct and inverse current components.

During line faults such as phase a to phase b the current magnitude will be higher than the ground faults. Since while any fault occurs on the transmission lines the fault current will flow through the ground and also faulted line. Figure 7 shows the double to ground fault as phase a phaseb ground fault. Here we can absorb the magnitude of current is less when compare with the line-line faults. Figure 8 shows the Direct current, inverse current and homopolar current for phase b c fault.

\subsection{Current Magnitude Calculated by Fuzzy for Faults}

In this system parameters are $200 \mathrm{kV}$ system voltage, source resistance as $0.8929 \Omega$, source impedance as 16.58 $\mathrm{mH}$. Here the faults as said to be a power quality variation they are classified as either disturbances or steady sate variations. This interferes the normal flow of current is known as fault. In such a condition the fault current will tends to move in either through ground or through affected line. Table 2 shows variation of current during fault condition, it may be either line fault or ground faults. The efficiency of the Adaline and fuzzy techniques in transmission line protection is shown in Table 3.

\section{Conclusions}

The Adaline and fuzzy logic controller is used to separate the oscillating and average powers separately in the test system based on the rule base. The fuzzy logic uses the real power, reactive power, direct axis current angle and inverse axis current angle as inputs. Based on instantaneous power theory direct and inverse currents are computed that is symmetrical components are calculated for fault identification in system.

Thus various current magnitudes are estimated for different type of unsymmetrical faults based on the instantaneous power theory and fuzzy logic controller. The current magnitude for line to line faults such as phase a-phase b fault or phase b to phase c faults or phase c to phase a faults is higher than the double line to ground faults as phase a to phase b to ground fault and so on. Thus the main objective of project is to identify the faults is done. This proposed system based Adaline and fuzzy classifies the various shunt faults and ground faults. Thus simulation results show the good performance and the accuracy in identifying the various transmission line 


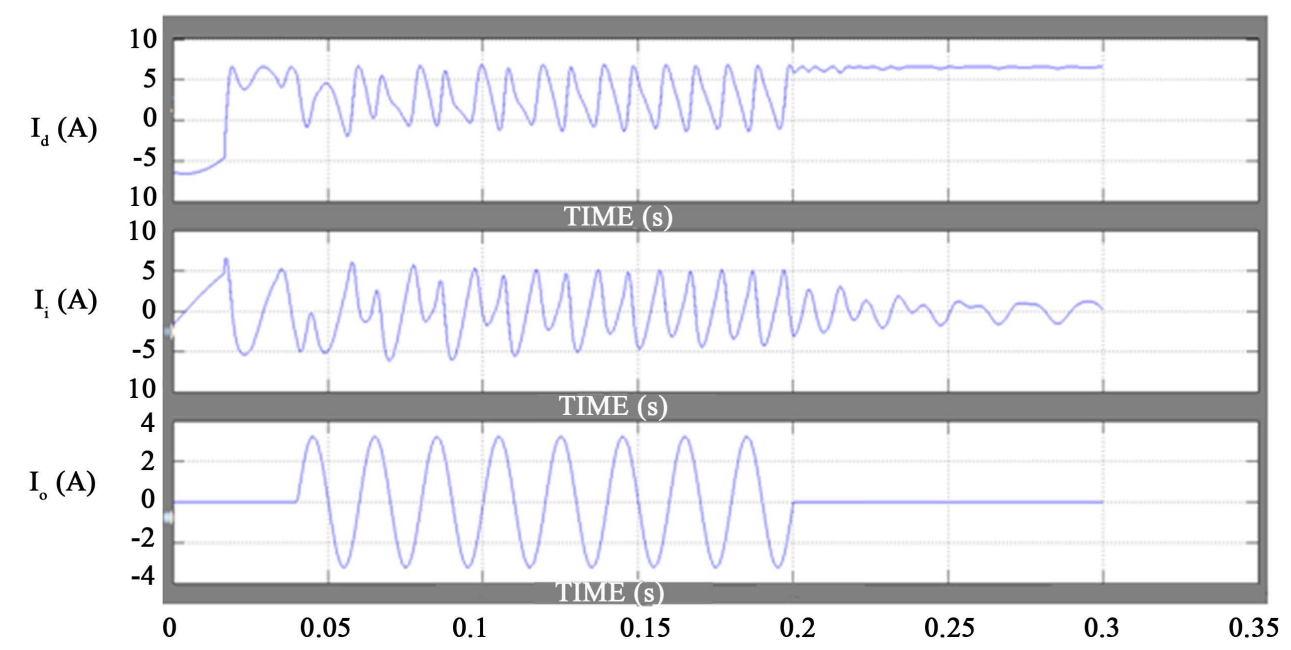

Figure 6. Direct current, inverse current and homopolar current for phase a ground fault.

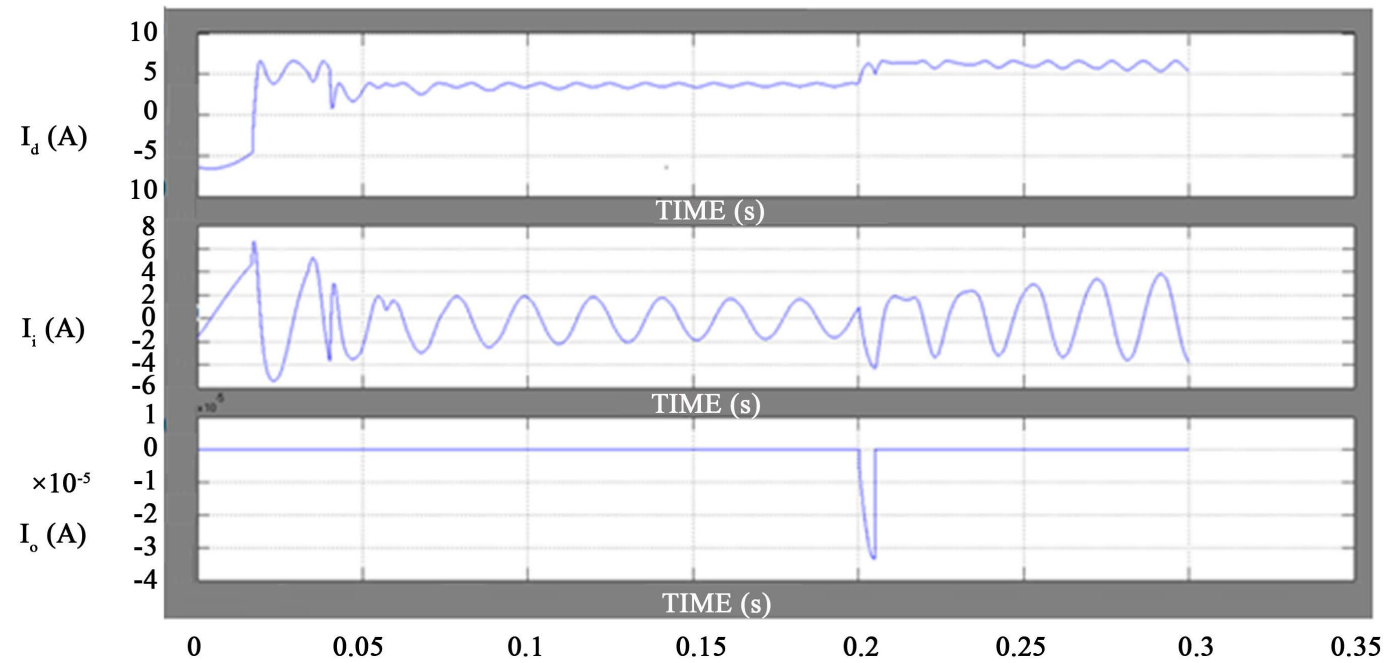

Figure 7. Direct current, inverse current and homopolar current for phase a $\mathrm{b}$ ground fault.

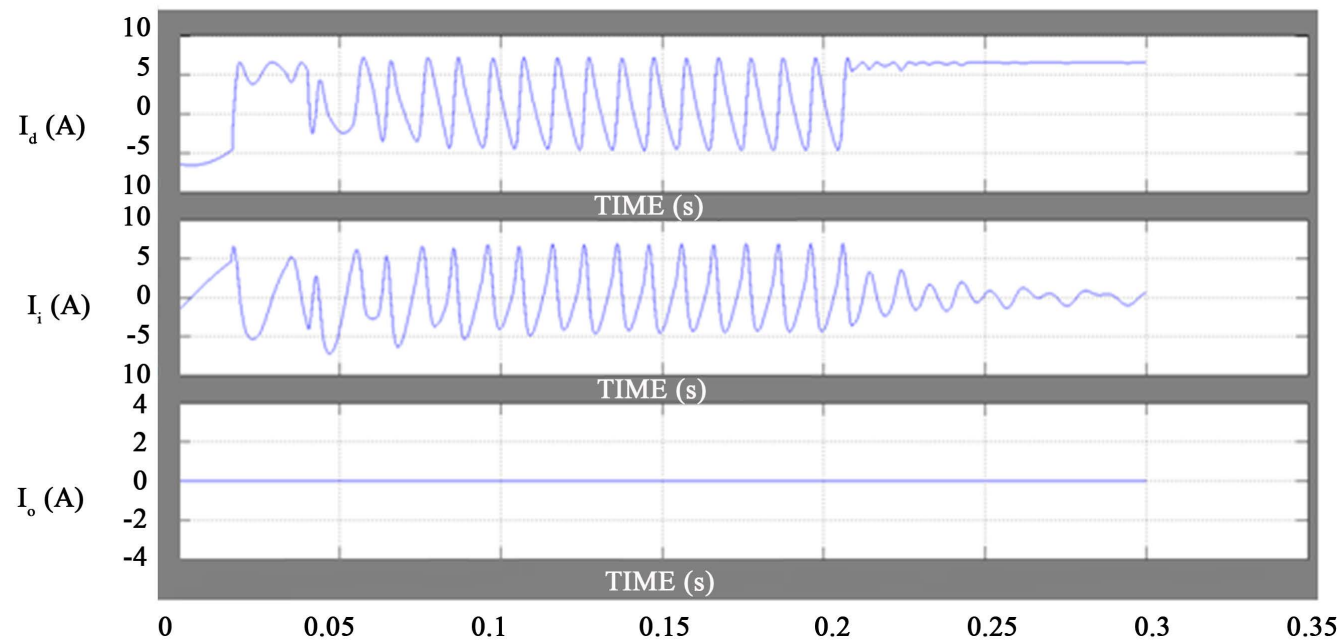

Figure 8. Direct current, inverse current and homopolar current for phase b c fault. 
Table 2. Transmission line fault identification.

\begin{tabular}{ccccc}
\hline \multirow{2}{*}{ Current Magnitude } & \multicolumn{2}{c}{ Normal condition } & \multicolumn{2}{c}{ During fault } \\
\cline { 2 - 4 } & Min I (kA) & MaxI (kA) & Min I (kA) & MaxI (kA) \\
\hline Phase a & 8.9581 & 10.0639 & 12.0936 & 14.6547 \\
Phase b & 8.8827 & 10.0233 & 12.0267 & 15.6329 \\
Phase c & 8.9481 & 10.3043 & 11.9689 & 14.8541 \\
\hline
\end{tabular}

Table 3. Fault current identificaion and comparison.

\begin{tabular}{ccccc}
\hline S. No & Fault Time (s) & Type of Fault & Adaline Results (P.u) & Fuzzy Results (kA) \\
\hline 1 & 0.04 & SL-G fault & 49.58 & 12.473 \\
2 & 0.04 & L-L fault & 97.21 & 15.063 \\
3 & 0.04 & L-L-G fault & 73.64 & 13.170 \\
\hline
\end{tabular}

faults. The fault can be protected by using fuzzy based differential relay and also can verify in the transmission system which is subjected any Facts controller and Wind farms are integrated to that system.

\section{References}

[1] Dalstein, T. and Kulicke, B. (1995) Neural Network Approach to Fault Classification for High Speed Protective Relaying. IEEE Transaction Power Delivery, 10, 1002-1011. http://dx.doi.org/10.1109/61.400828

[2] Bouthiba, T. (2005) Fault Detection and Classification Technique in EHV Transmission Lines Based on Artificial Neural Networks. European Transactions on Electrical Power, 15, 443-454. http://dx.doi.org/10.1002/etep.58

[3] Jiang, J.A., Chen, C.S. and Liu, C.W. (2003) A New Protection Scheme for Fault Detection, Direction Discrimination, Classification, and Location in Transmission Lines. IEEE Transaction Power Delivery, 18, 34-42. http://dx.doi.org/10.1109/TPWRD.2002.803726

[4] Nguyen, N.K., Flieller, D., Wira, P. and Abdeslam, D. (2009) Neural Network for Phase and Symmetrical Components Estimation in Power Systems. Proceedings of the 35th Annual Conference of the IEEE IESP, Portugal, November 2009, 3252-3257. http://dx.doi.org/10.1109/iecon.2009.5415210

[5] Phadke, G. and Thorp, J.S. (2009) Computer Relaying for Power Systems. 2nd Edition, Wiley, Hoboken. http://as.wiley.com/WileyCDA/WileyTitle/productCd-0470057130.html http://dx.doi.org/10.1002/9780470749722

[6] Mohamed, E.A., Talaat, H.A. and Khamis, E.A. (2010) Fault Diagnosis System for Tapped Power Transmission Lines. Electric Power Systems Research, 80, 599-613. http://dx.doi.org/10.1016/j.epsr.2009.10.030

[7] Song, Y.H., Xuan, Q.X. and Johns, A.T. (1997) Comparison Studies of Fiveneural Network Based Fault Classifiers for Complex Transmission Lines. Electric Power Systems Research, 43, 125-132. http://dx.doi.org/10.1016/S0378-7796(97)01168-1

[8] Dash, P.K., Pradhan, A.K. and Panda, G. (2001) Application of Minimal Radial Basis Function Neural Network to Distance Protection. IEEE Transaction Power Delivery, 16, 68-74. http://dx.doi.org/10.1109/61.905593

[9] Lin, W.-M., Yang, C.-D., Lin, J.-H. and Tsay, M.-T. (2001) A Fault Classification Method by RBF Neural Network with OLS Learning Procedures. IEEE Transaction Power Delivery, 16, 473-477. http://dx.doi.org/10.1109/61.956723

[10] Pasand, M.S., Zadeh, H.K. and Malik, O.P. (2003) Transmission Line Fault Detection and Phase Selection Is Using ANN. Proceedings of the International Conference on Power Systems Transients of the IPST, New Orleans. http://ipstconf.org/papers/Proc_IPST2003/03IPST05a-01.pdf

[11] Yousfi, F.L., Abdeslam, D.O. and Nguyen, N.K. (2010) Adaline for Fault Detection in Electrical High Voltage Transmission Line. Proceedings of the 36th Annual Conference on IEEE Industrial Electronics Society of the IECON, Glendale. http://dx.doi.org/10.1109/iecon.2010.5675309

[12] Karacasu, O. and Hocaoglu, M.H. (2011) An Adaline Based Arcing Fault Detection Algorithm for Singlepole Autoreclosers. Electric Power Systems Research, 81, 367-376. http://dx.doi.org/10.1016/j.epsr.2010.09.014

[13] Math Works, Matlab/Simulink R2008 (B) Software. www.mathworks.com

[14] Huishengwang and Keerthipala, W.W.L. (1998) Fuzzy Neuro Approach to Fault Classification for Transmission Line 
Protection. IEEE Transaction Power Delivery, 13, 1093-1104. http://dx.doi.org/10.1109/61.714467

[15] Zadeh, L.A. (1965) Fuzzy Sets. Journal of Information and Control, 8, 338-353. http://dx.doi.org/10.1016/S0019-9958(65)90241-X

[16] Aggarwal, R.K., Xuan, Q.Y., John, T., Li, F.R. and Bennett, A. (1999) A Novel Approach to Fault Diagnosis in Multicircuit Transmission Lines Using Fuzzy ARTmap Neural Networks. IEEE Transaction Neural Networks, 10, 12141221. http://dx.doi.org/10.1109/72.788660

[17] Akagi, H., Watanabe, E.H. and Aredes, M. (2007) Instantaneous Power Theory and Applications to Power Conditioning. Wiley/IEEE, Hoboken. https://books.google.co.in/books?isbn=047011892X http://dx.doi.org/10.1002/0470118938

[18] Das, B. and Vittal Reddy, J. (2003) Fuzzy Logic Based Fault Classification Scheme for Digital Distance Protection. IEEE Transaction Power Delivery, 20, 609-616.

\section{Submit or recommend next manuscript to SCIRP and we will provide best service for you:}

Accepting pre-submission inquiries through Email, Facebook, LinkedIn, Twitter, etc.

A wide selection of journals (inclusive of 9 subjects, more than 200 journals)

Providing 24-hour high-quality service

User-friendly online submission system

Fair and swift peer-review system

Efficient typesetting and proofreading procedure

Display of the result of downloads and visits, as well as the number of cited articles

Maximum dissemination of your research work

Submit your manuscript at: http://papersubmission.scirp.org/ 